\title{
THE RELATIONSHIP BETWEEN VISITOR SPENDING AND REPEAT VISITS: AN ANALYSIS OF SPECTATORS AT THE OLD MUTUAL TWO OCEANS MARATHON
}

\author{
Dr Martinette Kruger: TREES (Tourism Research in Economic Environs and Society), North- \\ West University. \\ Dr Karin Botha: TREES (Tourism Research in Economic Environs and Society), North-West \\ University. \\ Prof Melville Saayman: TREES (Tourism Research in Economic Environs and Society), North- \\ West University.
}

\begin{abstract}
PURPOSE: The purpose of this research is to determine the relationship between visitor spending patterns, and previous and planned return visits as well as demographic and trip characteristics of supporters to the Old Mutual Two Oceans Marathon held annually in Cape Town.

PROBLEM INVESTIGATED: Spectator sport is a significant segment of the tourism industry which also has a considerable economic impact on host communities. For this reason, communities and destinations have recognised and attempt to capitalise on hosting large sporting events. In this regard visitor spending is crucial since information concerning the latter can provide sport event organisers to focus their marketing efforts to attract optimal economic benefits. In addition, the relationship of previous visits to a sport event and intended re-visits to visitor spending has received increasing attention since it is believed that repeat visitation is associated with higher levels of expenditure. However limited attention is currently being paid to the relationship between spectator spending patterns and previous and planned return visits in a South African sport spectator context even though the latter has a direct impact on the future sustainability of an event.
\end{abstract}

METHODOLOGY: A supporter survey was done for the first time in 2010 (30 March - 2 April 2010) at the event and 430 questionnaires were completed. Factor analysis and regression analysis are used to analyse the data and to identify the relationship between repeat visits and visitor spending patterns.

FINDINGS: Results from this study shows that it is predominantly socio-demographic variables that influence travel behaviour. The significant socio-demographic determinants that influence spending per person are gender, language and province of origin while the only behavioural determinant was group size. The results also revealed that there is no significant relationship between spectator spending, repeat attendance and intention to re-visit. However, repeat attendance does have a significant influence on spectators' intention to re-visit and spectators who have attended the race more times have a higher intention to revisit in the future.

ORIGINALITY AND CONCLUSION: Results from his innovative study showed that although no statistically significant relationship was established, a strong relationship between repeat visits and intention to revisit was found. A significant contribution to the literature is evident since the focus is on spectators at a sports event as opposed to participants. It was the first study of its kind in South Africa and the importance of the role and function of spectators at an event is highlighted. As a further contribution, prominent differences regarding the participants were evident when compared to previous studies on participants at other South African sports events. Event organisers can use this information to effectively promote the event in order to attract supporters and to generate revenue for Cape Town during the event but especially months after the race. The latter will also greatly contribute to the long-term sustainability of the marathon.

KEY WORDS: Sport events, Old Mutual Two Oceans Marathon, visitors spending, repeat visits, sustainability 


\section{INTRODUCTION AND THEORETICAL BACKGROUND}

Gibson (1998:155), Bull and Weed (1999:143) and Ritchie (2005:158) indicated that travel related to sport and physical activity can be regarded as one of the fastest growing segments of the tourism industry. Gratton et al. (2005:233) furthermore point out that the phenomenal growth in sport tourism is not surprising considering the broad range of benefits that accrue to both the host country and the host city from the staging of sport events. Potential benefits of sport tourism include the following (Getz, 1998:9; Kotze, 2006:285; Hinch \& Higham, 2004:88; Turco, 1998:3; Scott \& Turco, 2007:41; Coleman, 2004:11; Gratton, Dobson \& Shibli, 2000:18; Saayman, Saayman \& du Plessis, 2005:212; Preuss, Seguin \& O'Reilly, 2007:6; Robinson \& Trail, 2005:58): attract high-yield visitors, especially repeaters; generate a favourable image of the destination; develop new infrastructure; ensure longterm economic benefits by stimulating spending in the host community; use the media to extend the normal communications reach; generate increased rate of tourism growth or a level of higher demand; spread tourism geographically and seasonally; improve the organisational, marketing, and bidding capability of the community; secure a financial legacy for management of new sport facilities; maximise the use of, and revenue for, existing facilities; and increase community support for sport and sport-events.

One such event is the Old Mutual Two Oceans Marathon (hereafter referred to as Two Oceans). This marathon takes place towards the end of the high tourist season of the Western Cape, during the Easter weekend and is known as the most beautiful marathon in the world (Kotze, 2006:287). The race provides a large economic injection for the economy of Cape Town which is mainly due to fact that the event attracts over 15000 participants each year (Kotze, 2006:291). However, for any sporting event to be successful and profitable it not only needs sports participants but also spectators or attendees (Gibson, 1998). Cassidy (2005:4) and Bull and Weed (1999:143) state that sport spectators are estimated to be worth millions to the global economy which suggest that they are a valuable niche market segment which should be understood (Cannon \& Ford, 2002; Gibson, 1998:50). According to Wann, Melnick, Russel and Pease (2001:2) sport spectators are those individuals who actively witness a sporting event in person or through some form of media (radio and television for example). Wann et al. (2001:2) furthermore point out that the value of sport spectators lies in the fact that these individuals are interested in sport and as a result spend a considerable amount of money to actively follow a sport, team, and/or athlete. Standheven and De Knop (1999:4) add that spectator vacations are also increasingly popular with huge number of visitors attracted to sports events. However, not all supporters are equally passionate and fanatical (Redden \& Steiner, 2000) and neither are they all totally loyal or engrossed in sport history (Stewart, Smith \& Nicholson, 2003:206). Some spectators furthermore attend events on a regular basis, while others attend only on special occasions and some spend money to attend an event while other prefer to watch paid television sport channels (Stewart et al., 2003:206). For this reason, sport managers, merchandisers, television network producers, advertisers and corporate sponsors need to attract sport consumers and increase the consumption of sport-related products (McDonald, Milne \& Hong, 2002:100).

Hence it is important to analyse and understand the heterogeneity and complexity of sport spectators' behaviours and attitudes (Bouchet et al., 2010:2). Bouchet et al. (2010:2) add that this specific knowledge is particularly crucial for sport managers and organisers, as it would help them to categorise their demand accurately, which in turn would allow them to target and satisfy the appropriate market segments. Scott and Turco (2009:42) and Cannon and Ford (2002) furthermore emphasise that distinguishing sport event tourists (spectators) by their spending behaviours will lead to more accurate economic impact estimations as well as increased intended re-visits. The latter is especially important seeing as sporting events may experience significant fluctuations in attendance, spectator market segment proportionality and spending from year to year (Scott \& Turco, 2009:52).

Preuss, Seguin and O'Reilly (2007:9) indicate that there are empirical evidence that different sport events attract supporters of different ages and genders. According to Cassidy (2005:1) marketers and organisers need to be aware of the driving forces which influence these spectators' decision to attend a specific sport event and their consequent behaviour during the event. This is especially due to the fact that sport events have an interest in high value sport tourists, that is those who will deliver the greatest net benefit to the host economy, since investments in sport events are often justified by estimates of tourist spending or 'returns' (Scott \& Turco, 2007:41). With the afore-mentioned in mind, 
Gratton, Dobson and Shibli (2000:22) revealed in their study of the economic impact of six major sport events, that since athletics is spectator-driven, $75 \%$ of total additional expenditure was generated by visiting spectators to the International Amateur Athletics Federation Grand Prix held in Sheffield. Spectators to the Two Oceans therefore have the potential to have a considerable economic impact and repeat visitation has to be encouraged. In order to achieve the latter, the relationship between spending behaviour and repeat visitation of spectators to the event needs to be established. In addition to repeat behaviour, this understanding can lead to spectator satisfaction, increased positive word-of-mouth (Kotler, 1994), increased market share (Anderson, Fornell \& Lehmann, 1994) as well as a sustainable and profitable event (Anderson \& Mittal, 2000; Kotler, 1994).

Based on the latter, the relationship between repeat visits to an event and visitor spending is receiving increasing attention (Cannon \& Ford, 2002). This is largely due to the fact that the increase in sport events has resulted in intense competition for spectator spending and spectator sport events are finding it more difficult to remain as profitable as in the past (Lachowetz, 2001:25). Additionally, watching sport on television in the comfort of one's living room is one of the major threats to spectators attending sport events. Another threat is other forms of entertainment or recreation activities available. Understanding the expenditure patterns of spectators is thus vital since sport events can then focus their marketing efforts to attract optimal economic benefits (Regan \& Damonte, 1999). However, along with this, satisfying spectators is just as important (van Leeuwen, Quick \& Daniel, 2002:100; Yoshida \& James, 2010:338) and over the past few years, measures have been taken to restructure sport events so as to increase attendance (Kuenzel \& Yassim, 2007:43). A deeper understanding of spectators is thus needed to ensure that the right mix of elements is provided to influence a positive event experience and to enhance the level of satisfaction (Kuenzel \& Yassim, 2007:43). This will not only help to convert first-time supporters and new spectators into becoming committed supports but also increase visitor spending resulting in a greater economic impact (Kuenzel \& Yassim, 2007:43).

Saayman and Saayman (1997:162) indicated that the economic impact of spectators at a sport event is influenced by the magnitude of spectator spending, the number of spectators attending the event, the number of days spent in the host city and circulation (multiplier) of supporter spending through the economy of the host city and community. The spending by spectators to an event is furthermore the first input in the economic impact assessment and a true understanding of visitor spending and the factors that influence the amount that certain visitors spend are therefore an essential input in any economic impact study (Saayman, Saayman \& du Plessis, 2005:212). The desire to understand the spending behaviour of sport spectators has thus been a long-standing goal for sport marketers (Stewart, Smith \& Nicholson, 2003:206).

With the afore-mentioned in mind, Crompton (1995) emphasises that it is important to take into consideration the fact that among sport event spectators, market segments may include residents, tourists, and those visiting the host community for other reasons, or casuals. It is thus unclear which segments of the sport spectator market are most likely to produce the greatest economic benefits (and fewest costs) for the host city (Scott \& Turco, 2007:42). Based on this, Cannon and Ford (2002) recommend that an analysis of spending patterns of spectators can provide a measure of the overall impact of visitor spending in the community due to a sport event and is also important to host communities for planning, evaluative and promotional purposes. However, even though there are a number of demographic variables that contribute to spectators' spending (Brown, Brusser \& Baloglu, 2008:2), the effects of spectators' demographic and trip characteristics on visitor expenditure patterns have received limited attention in tourism and especially marathon event literature (Cannon \& Ford, 2002). It is furthermore suggested that while past works have identified the important motivational and behavioural differences, they frequently provide only partial explanations for sport consumer spending behaviour (Stewart et al., 2003:206). Stewart et al. (2003:206) further indicated that previous research are often constrained by an overemphasis on social-psychological traits, and give only limited attention to the cultural and economic context in which behaviours take place.

Concerning spending behaviour, Standeven and DeKnop (1999) postulated that a sport tourist can be characterised as individuals that were more likely to travel long haul, stay more days, stay in costlier accommodation and spend more per day. Irwin and Sandler (1998) on the other hand found that spectators spent the most on lodging and retail shopping and spectators with a particular team 
affiliation spent more time and money at the destination. Generally, the key factors which have been identified as having a relationship with sport spectator expenditures have included age, gender, family structure and values, household income, visitor origin, party size, trip activities and trip duration, friendship groups, the social milieu in which sport consumers run their daily lives, the class or subculture to which they belong, their sensitivity to price, and the cost of sport activities (Robinson \& Trail, 2005; Fort, 2003, Hunt et al., 1999; Wann et al., 2001; Wicker, Breuer \& Pawlowski, 2009:2; Cannon \& Ford, 2002; Saayman et al., 2005; Wang, Rompf, Severt \& Peerapatdit, 2006; Dietz-Uhler, Harrick, End \& Jacquemotte, 2000).

The literature furthermore shows that the cost for marketers to attract repeat visitors is significantly lower than for first-time visitors (Reid \& Reid, 1993; Oppermann, 2000). Repeat visitors are also significantly different than first-time visitors in factors such as trip behaviour, intentions to revisit, socioeconomic characteristics, and benefits sought (Cannon \& Ford, 2002). Alegre and Juaneda (2006:685) point out that the benefits that a high degree of loyalty represents for an event especially depend on possible differences in expenditures between first-time and repeat visitors. With the latter in mind, it is essentially argued that repeat visitors spent more money (Oppermann, 2000:78). A possible explanation for this finding is because repeat visitors perceive the overall value for money to be more satisfactory than first-time visitors (Kozak \& Rimmington, 2000) and satisfaction leads to repeat action (Baker \& Crompton, 2000; Kozak, 2001:784). In support of the latter, Matheson (2006:7) explains that satisfied sport spectators may enjoy their visit to the host city during the event and return later raising future tourist revenues for the area.

For this reason it is vital for sport events to determine who the quality event tourist is and how to cultivate that market segment (Getz, 1998:13; Bouchet, Bodet, Bernache-Assollant \& Kada, 2010:2). Developing an understanding of who sport spectators are and what factors influence their consumption behaviour is critical to reaching the above (McDonald, Milne \& Hong, 2002:100; Stewart, Smith \& Nicholson, 2003:206). A better understanding of spectators at sport events will enable organisers and policy makers to formulate more effective, consumer-centric, marketing strategies (for example destination advertising and demand forecasting) leading to larger event attendance resulting in greater economic activity (Regan, Carlson \& Rosenberger, 2009:6).

\section{PROBLEM STATEMENT AND PURPOSE}

Spectator sport is a significant segment of the tourism industry which also has a considerable economic impact on host communities. For this reason, communities and destinations have recognised and attempt to capitalise on hosting large sporting events. In this regard visitor spending is crucial since information concerning the latter can provide sport event organisers to focus their marketing efforts to attract optimal economic benefits. In addition, the relationship of previous visits to a sport event and intended re-visits to visitor spending has received increasing attention since it is believed that repeat visitation is associated with higher levels of expenditure. However limited attention is currently being paid to the relationship between spectator spending patterns and previous and planned return visits in a South African sport spectator context even though the latter has a direct impact on the future sustainability of an event. Based on the afore-mentioned discussion, the aim of this study is to determine the relationship between spectator spending patterns, and previous and planned return visits as well as demographic and trip characteristics of supporters to the Two Oceans.

\section{METHOD OF RESEARCH}

A structured questionnaire was used to collect the data. The method of research used will be discussed under the following headings: (i) the questionnaire, (ii) sampling method, (iii) survey and (iv) statistical analysis.

\section{The Questionnaire}

A questionnaire was developed based on the works of Hunt, Bristol and Bashaw (1999), Stewart, Smith and Nicholson (2003) and McDonald, Milne and Hong (2002) and adapted for the Old Mutual Two Oceans Marathon. The questionnaire was subdivided into three sections. Sections A and B captured demographic details (gender, home language, age, occupation, home province, marital status and preferred accommodation) as well as spending behaviour (number of persons paid for, 
length of stay and expenditure) while Section $C$ measured the motivational factors for supporting the race. Fifteen items were measured in the motivation section on a five-point Likert scale and respondents were asked to indicate how important they considered each item on the scale $(1=$ not at all important; 2 = less important; $3=$ neither important nor less important; $4=$ very important and $5=$ extremely important). For the purposes of this article, the information obtained from all the sections was used.

\section{Sampling method}

A total of 430 completed questionnaires were included in the analysis. According to Israel (2009:6), from a population of $100000(\mathrm{~N}), 398$ respondents $(\mathrm{n})$ are seen as representative and result in a $95 \%$ level of confidence with a $\pm 5 \%$ sampling error. Since approximately 12000 spectators supported the race (Kruger, Saayman, Saayman \& Rossouw, 2010:32), the number of completed questionnaires is greater than the required number of questionnaires.

\section{Survey}

An onsite intercept survey was undertaken, with field workers handing out 450 questionnaires on-site at the University of Cape Town (UCT) Sports Grounds in Cape Town on the day of the race, 3 April 2010. Spectators were approached while they were watching the athletes enter the sports grounds. The field workers were trained to ensure that they understood the aim of the study as well as the questionnaire. Respondents were briefed about the purpose of the research beforehand to ensure that they participated willingly and responded openly and honestly.

\section{Statistical Analysis}

Microsoft $^{\odot}$ Excel $^{\odot}$ was used for data capturing while SPSS (SPSS Inc, 2007) was used for the analysis of data. This study comprised three stages. Firstly, a general profile of spectators was compiled. Secondly, a principal component factor analysis, using an Oblimin rotation with Kaiser Normalisation was performed on the 15 motivational items, to explain the variance-covariance structure of the set of variables through a few linear combinations of these variables. The Kaiser-Meyer-Olkin measure of sampling adequacy was used to determine whether the covariance matrix is suitable for factor analysis. Kaiser's criteria for the extraction of all factors with eigenvalues larger than 1 were used. All items with a factor loading above 0.3 were considered as contributing to a factor, whereas all items with factor loadings lower than 0.3 were considered as not correlating significantly with this factor (Steyn, 2000). Any item that cross-loaded on two factors, with factor loadings greater than 0.3 , was categorised in the factor where interpretability was best. A reliability coefficient (Cronbach's alpha) was computed for each factor to estimate the internal consistency of each factor. All factors with a reliability coefficient above 0.6 were considered in this study to have acceptable internal consistency. The average inter-item correlations were also computed as another measure of reliability. According to Clark and Watson (1995), the average inter-item correlation should lie between 0.15 and 0.55 .

Thirdly, regression analysis was performed to identify the relationship between spectator spending, repeat visits and intention to re-visit. The latter was analysed in three ways:

a) A multiple regression analysis was performed to identify the determinants of spectator spending.

b) A logistic regression analysis was performed to analyse the determinants of previous (repeat) visitation to the Two Oceans.

c) A logistic regression analysis to analyse the determinants of intention to re-visit and support the Two Oceans in the future.

Although the survey alone will provide some insight into the characteristics of spectator spending at the Two Oceans, such analysis does not describe the relative strength or the significance of the relationship between spending and its different determinants. Such an analysis requires a regression analysis. There are a number of different types of regression analysis that can be used. In standard multiple regression, all the independent (or predictor) variables are entered into the equation simultaneously. Each independent variable is evaluated in terms of its predictive power, over and above that offered by all the other independent variables (Pallant, 2007:147). $R^{2}$ gives the proportion of variance in spending that is explained by the predictors included in the model. $A R^{2}$ of 0.25 or larger can be considered as practically significant (Ellis \& Steyn, 2003:53). The adjusted $R^{2}$ indicates how much variance in the outcome would be accounted for if the model had been derived from the population from which the sample was taken (Field, 2005:723). The adjusted $R^{2}$ therefore gives an 
idea of how well the regression model generalises and, ideally, its value needs to be the same or very close to the value of $R^{2}$ (Field, 2005:188).

However, while multiple regression is ideal to identify the significant determinants of spectators' spending, it is not suitable to analyse the determinants of repeat visits and spectators' intention to revisit. This is because for multiple regression, the dependent variable is a continuous variable, with scores that are reasonably normally distributed. Logistic regression can be used to test models to predict categorical outcomes with two or more categories (Pallant, 2007:168; Field, 2005:218). Therefore logistic regression models will be used to analyse the determinants of repeat visitation and intention to re-visit as these were categorical questions in the questionnaire.

Most questions have multiple choice responses or were answered on a 5-point Likert scale. The dependent (predicted) variables are spending per person, number of time the race has been supported and intention to support again. Spending per person was calculated by adding the spending of the respondent on the various components asked. This amounted to total spending, which was then divided by the number of people whom the respondent was paying for during the trip, to give spending per person. With regards to the number of times the Two Oceans has been supported, repeat spectators were distinguished from first-timers. The socio-demographic and behavioural determinants used in the analysis are described in Table 1.

Table 1: Questions used and their descriptions

\begin{tabular}{|l|l|l|l|}
\hline Category & Question description & Coding & Variable \\
\hline \multirow{4}{*}{$\begin{array}{l}\text { Socio- } \\
\text { demographics }\end{array}$} & Home language & Afrikaans $=1 ;$ Engels $=0$ & LANGUAGE \\
\cline { 2 - 4 } & Gender & Male $=1 ;$ Female $=0$ & GENDER \\
\cline { 2 - 4 } & Age & Open question & AGE \\
\cline { 2 - 4 } & Province & Western Cape $=1 ;$ Other $=0$ & PROVINCE \\
\hline \multirow{5}{*}{ Behavioural } & Group size & Open question & GROUP SIZE \\
\cline { 2 - 4 } & Number of people paid for & Open question & PEOPLE PAID \\
\cline { 2 - 4 } & Number of nights in Cape Town & Open question & FOR NIGHTS \\
\cline { 2 - 4 } & Number of times supported & Repeat $=1 ;$ First time $=0$ & TIMES \\
\cline { 2 - 4 } & Intention of repeat support & Yes $=1 ;$ No $=0$ & SUPPORT \\
& & & AGAIN \\
\hline
\end{tabular}

The dummy variables are coded 1 and 0 according to the table above. Along with these variables, travel motives were also included in the analysis. The predictors included quantitative variables like age, length of stay, number of times Two Oceans was supported, and the size of the travel party. It also included qualitative variables that indicate the presence or absence of a quality or attribute that may influence total spending at the race as well as repeat visitation and intention to re-visit. Such qualitative (or dummy) variables were constructed, as indicated in Table 1, for the following variables: gender, province and language. The results of the statistical analyses will be discussed in the next section.

\section{RESULTS}

The results will be discussed in two sections. Firstly, an overview of the profile of spectators at the Old Mutual Two Oceans Marathon will be presented followed by the results of the regression analysis.

\section{Profile of spectators at the Old Mutual Two Oceans Marathon}

Based on the results captured and displayed in Table 2, most of the spectators are female; they are predominantly English-speaking, on average 37 years old and originate from the Western Cape or Gauteng provinces. A large proportion of visitors are in a professional occupation, travel in a group of five people and are financially responsible for two persons during their visit. They stay an average of six nights in Cape Town; they spend an average of R3202.00 during the race and have supported the race an average of four times. 
M. Kruger

K. Botha

M. Saayman
The relationship between visitor spending and repeat visits:

An analysis of spectators at the Old Mutual two oceans marathon

Table 2: Profile of spectators at the Two Oceans

\begin{tabular}{|l|l|}
\hline CATEGORY & PROFILE OF SPECTATORS \\
\hline Gender & Female (61\%); Male (39\%) \\
\hline Home language & English (60\%), Afrikaans (31\%) \\
\hline Age & Average age: 37 years \\
\hline Province of residence & Western Cape (52\%) and Gauteng (20\%) Provinces \\
\hline Occupation & Professional (25\%), Student (19\%), Management (11\%) \\
\hline Number of nights in Cape Town & Average of 6 nights in Cape Town \\
\hline Number of people paid for & Average of 2 persons \\
\hline Group size & Average of 5 persons \\
\hline Number of times participated & Average 4 times \\
\hline Expenditure per group & Average of R3202.00 \\
\hline
\end{tabular}

\section{Results of the factor analysis}

A principal component factor analysis using an Oblimin rotation with Kaiser Normalisation was performed and the three factors that were identified were labelled according to similar characteristics (Table 3). These three factors accounted for $65 \%$ of the total variance. All factors had relatively high reliability coefficients ranging from 0.68 (the lowest) to 0.92 (the highest). The average inter-item correlation coefficients with values between 0.42 and 0.67 also imply internal consistency for all factors. Moreover, all items loaded on a factor with loading greater than 0.3 and the relatively high factor loadings indicate a reasonably high correlation between the delineated factors and their individual items. The Kaiser-Meyer-Olkin measure of sampling adequacy of 0.90 also indicates that patterns of correlation are relatively compact and yield distinct and reliable factors (Field, 2005:640). Barlett's Test of Sphericity also reached statistical significance $(p<0.000)$, supporting the factorability of the correlation matrix (Pallant, 2007:197).

\section{Table 3: Factor analysis results of Old Mutual Two Oceans Marathon supporters'} motivations

\begin{tabular}{|l|c|c|c|c|}
\hline MOTIVATION FACTORS AND ITEMS & $\begin{array}{c}\text { FACTOR } \\
\text { LOADING }\end{array}$ & $\begin{array}{c}\text { MEAN } \\
\text { VALUE }\end{array}$ & $\begin{array}{c}\text { RELIABILITY } \\
\text { COEFFICIENT }\end{array}$ & $\begin{array}{c}\text { AVERAGE } \\
\text { INTER-ITEM } \\
\text { CORRELATION }\end{array}$ \\
\hline Factor 1: Event attractiveness & & 3.40 & 0.92 & 0.56 \\
\hline To see world-class athletes compete & 0.81 & & & \\
\hline Because I enjoy watching marathon running & 0.80 & & & \\
\hline It is a well-known international event & 0.80 & & & \\
\hline $\begin{array}{l}\text { I enjoy the camaraderie associated with } \\
\text { marathon running }\end{array}$ & 0.78 & & & \\
\hline The atmosphere of the Two Oceans & 0.77 & & & \\
\hline I support and attend it annually & 0.73 & & & \\
\hline To be part of the Two Oceans & 0.73 & & & \\
\hline Because the event is well-organised & 0.63 & & & \\
\hline To meet new people & 0.60 & & & \\
\hline It is a sociable event & 0.59 & & & \\
\hline Factor 2: Support and socialisation & & 3.94 & 0.68 & \\
\hline To support a friend or family member & 0.90 & & & \\
\hline To spend time with family & 0.60 & & & \\
\hline To spend time with friends & 0.35 & & & \\
\hline Factor 3: Escape and relaxation & & 3.28 & 0.80 & \\
\hline $\begin{array}{l}\text { To get away from my normal routine and } \\
\text { stress }\end{array}$ & 0.81 & & & \\
\hline To relax & 0.73 & & & \\
\hline TOTAL VARIANCE EXPLAINED & $65 \%$ & & & \\
\hline
\end{tabular}


Factor scores were calculated as the average of all items contributing to a specific factor so that they can be interpreted on the original 5 -point Likert scale of measurement $(1=$ not at all important; $2=$ less important; $3=$ neither important nor unimportant; $4=$ very important; $5=$ extremely important). As shown in Table 2, the following motivations were identified: Event attractiveness, Support and socialisation and Escape and relaxation. Not surprisingly, Support and socialisation (Factor 2) obtained the highest mean value (3.94) and was considered as the most important motive to attend the Two Oceans. The reliability coefficient was 0.68 while the average inter-item correlation was 0.42 . Event attractiveness (Factor 1) had the second highest mean value (3.40) and this factor had a reliability coefficient of 0.92 and an inter item correlation of 0.56 . Escape and relaxation (Factor 3 ) obtained the lowest mean value (3.28). The reliability coefficient was 0.80 and the average inter-item correlation was 0.67 . These results correspond with general travel motivation literature that indicated that sport spectators are mainly motivated by psychological factors (to escape, to experience the beauty of the sport and entertainment), and socio-cultural factors (to spend time with family, group affiliation and personal enhancement) (Wann, 1995; Trail \& James, 2001; Milne \& McDonald, 1999; Weed \& Bull, 2004; Guilianotti, 2002). These factor scores were included, along with the sociodemographic and behavioural determinants (Table 1) in further analysis.

\section{Results from the linear regression analysis: Spending per person}

As indicated in Table 4, 22\% $\left(R^{2}\right)$ of the variance in spending per person is explained by the predictors included in the linear regression analysis. The $F$-ratio is significant with $p<0.001$, indicating that a significant proportion of the variance in spending is explained by the included predictors. The results indicate that gender, language and province of origin are the most significant socio-demographic indicators. With regard to gender, the results show that male spectators tend to spend more than females. The negative sign in the language category indicates that English-speaking spectators spend more at the race than Afrikaans-speaking spectators. The negative sign in the province of origin category also indicates that spectators from the Western Cape spend less than spectators from other provinces. Age showed no significant influence on higher spending. The sign of the coefficient however indicate that older spectators tend to spend more at the race.

Group size is the only significant behavioural indicator. The negative sign in this category indicates that the spectators who travel with fewer people tend to spend more per person. Length of stay (nights) and the number of times supported also showed no significant influence on higher spending. The negative sign of the coefficients indicate that spectators who stay fewer nights in Cape Town and who have supported the event fewer times tend to be higher spenders. None of the travel motives were also significant. When interpreting the sign of the coefficient, visitors who are motivated more by Event attractiveness tend to have a higher spending per person compared to spectators who are motivated by Support and socialisation and Escape and relaxation. 
Table 4: Results from linear regression

\begin{tabular}{|c|c|c|c|c|c|}
\hline \multicolumn{5}{|c|}{ Dependent Variable: Total spending per person } & \\
\hline & B & Std. Err. of B & Beta & $t(130)$ & p-level \\
\hline C & 5919.02 & 1525.27 & & 3.881 & 0.000 \\
\hline Event attractiveness & 107.89 & 325.48 & 0.036 & 0.331 & 0.741 \\
\hline Support and socialisation & -327.25 & 332.56 & -0.102 & -0.984 & 0.327 \\
\hline Escape and relaxation & -279.01 & 245.61 & -0.108 & -1.136 & 0.258 \\
\hline Age & 20.27 & 21.22 & 0.083 & 0.956 & 0.341 \\
\hline Group size & -194.07 & 60.24 & -0.272 & -3.222 & $0.002^{*}$ \\
\hline Nights & -57.65 & 61.41 & -0.084 & -0.939 & 0.350 \\
\hline Times supported & -76.96 & 74.90 & -0.089 & -1.028 & 0.306 \\
\hline Gender & 1403.60 & 543.59 & 0.210 & 2.582 & $0.011^{*}$ \\
\hline Language & -1313.31 & 558.63 & -0.204 & -2.351 & $0.020^{*}$ \\
\hline Province & -2018.30 & 799.99 & -0.226 & -2.523 & $0.013^{*}$ \\
\hline $\mathbf{R}$ & 0.47 & & $F(20,130)$ & 3.76 & \\
\hline $\mathbf{R}^{2}$ & 0.22 & & & 0.001 & \\
\hline Adjusted $\mathbf{R}^{2}$ & 0.15 & & $\begin{array}{l}\text { Std. Error of } \\
\text { estimate }\end{array}$ & 2951.62 & \\
\hline
\end{tabular}

\section{Results from the logistic regression analysis: Repeat attendance}

Direct logistic regression was performed to assess the impact of a number of factors on the likelihood that spectators at the Two Oceans would be repeat supporters. The model contained nine independent variables (spending per person, gender, language, province, nights, group size and the travel motives Event attractiveness, Support and socialisation and Escape and relaxation). The full model containing all predictors was statistically significant, $X^{2}(9, N=137)=32.56, p<0.001$, indicating that the model was able to distinguish between factors that influence repeat attendance and those that do not. The model as a whole explained between 21.2\% (Cox and Snell R square) and $28.7 \%$ (Nagelkerke R squared) of the variance in repeat attendance, and correctly classified $75.2 \%$ of the cases. 
Table 5: Results from logistic regression: Repeat attendance

\begin{tabular}{|l|c|c|c|c|c|c|}
\hline \multicolumn{1}{|c|}{ C } & B & S.E. & Wald & df & Sig. & Odds Ratio \\
\hline Spending per person & .000 & .000 & .275 & 1 & .600 & 1.000 \\
\hline Gender & -.435 & .432 & 1.013 & 1 & .314 & .647 \\
\hline Language & .334 & .430 & .603 & 1 & .437 & 1.397 \\
\hline Province & .250 & .659 & .144 & 1 & .705 & 1.284 \\
\hline Event attractiveness & 1.045 & .272 & 14.778 & 1 & $.000^{*}$ & 2.842 \\
\hline Support and socialisation & -.538 & .264 & 4.150 & 1 & $.042^{*}$ & .584 \\
\hline Escape and relaxation & -.350 & .213 & 2.697 & 1 & .101 & .705 \\
\hline Nights & -.131 & .058 & 5.194 & 1 & $.023^{*}$ & .877 \\
\hline Group size & .008 & .045 & .034 & 1 & .853 & 1.008 \\
\hline \multicolumn{1}{|c|}{ Constant } & 1.216 & 1.187 & 1.050 & 1 & .305 & 3.374 \\
\hline
\end{tabular}

As shown in Table 5, only length of stay (nights) and the travel motives Event attractiveness and Support and Socialisation have a significant influence on repeat attendance. The negative sign of the coefficient in the nights' category indicates that spectators who stay fewer nights in Cape Town tend to be repeat supporters. With regard to the significant travel motives, spectators who are motivated by Event attractiveness are more likely to be repeat spectators while the opposite result is found for spectators who are rather motivated by Support and socialisation. The strongest predictor of repeat attendance was the motive Event attractiveness, recording an odds ratio of 2.84. This indicates that repeat spectators, who are motivated by this factor, were over two times more likely to attend the race again than those who were not motivated by this factor, controlling for all other factors in the model. The odds ratio of .877 for nights was less than 1 , indicating that for every additional night spent in Cape Town, spectators were .877 times less likely to be repeaters, controlling for all other factors in the model.

The other socio-demographic and behavioural variables do not have a statistical significant influence on repeat attendance. However, when interpreting the sign of the coefficients it seems that female, Afrikaans-speaking spectators from the Western Cape, who spend more and travel with more people to attend the race, tend to be repeat supporters. Escape and relaxation also showed not significant influence on repeat attendance. The negative sign of the coefficient does however indicate that spectators, who are motivated by this factor, are not inclined to be repeat supporters.

\section{Results from the logistic regression analysis: Intention to re-visit}

Direct logistic regression was also performed to assess the impact of a number of factors on the likelihood that spectators at the Two Oceans would return to the event. The model contained nine independent variables (spending per person, gender, language, nights, group size, times supported and the travel motives Event attractiveness, Support and socialisation and Escape and relaxation). The full model containing all predictors was statistically significant, $X^{2}(9, N=137)=26.83, p<0.001$, indicating that the model was able to distinguish between factors that influence repeat attendance and those that do not. The model as a whole explained between $17.8 \%$ (Cox and Snell R square) and $28.6 \%$ (Nagelkerke R squared) of the variance in repeat attendance, and correctly classified $82.5 \%$ of the cases. 
Table 6: Results from logistic regression: Intention to re-visit

\begin{tabular}{|l|c|c|c|c|c|c|}
\hline \multicolumn{1}{|c|}{ C } & B & S.E. & Wald & df & Sig. & Odds Ratio \\
\hline Spending per person & .000 & .000 & .023 & 1 & .879 & 1.000 \\
\hline Gender & .938 & .564 & 2.772 & 1 & .096 & 2.556 \\
\hline Language & .738 & .557 & 1.755 & 1 & .185 & 2.091 \\
\hline Event attractiveness & .608 & .305 & 3.981 & 1 & $.046^{*}$ & 1.837 \\
\hline Support and socialisation & -.343 & .318 & 1.163 & 1 & .281 & .710 \\
\hline Escape and relaxation & .147 & .238 & .381 & 1 & .537 & 1.158 \\
\hline Nights & -.038 & .047 & .662 & 1 & .416 & .963 \\
\hline Group size & .061 & .075 & .655 & 1 & .418 & 1.062 \\
\hline Times supported & .321 & .159 & 4.073 & 1 & $.044^{*}$ & 1.378 \\
\hline \multicolumn{1}{|c|}{ Constant } & -.948 & 1.427 & .441 & 1 & .507 & .388 \\
\hline
\end{tabular}

Table 6 shows that Event attractiveness as a motive to support the Two Oceans and the number of times supported were the only significant behavioural variables which had an influence on spectators' intention to re-visit. The strongest predictor of intention to revisit was the motive Event attractiveness, recording an odds ratio of 1.84. The odds ratio for times supported was also more than one (1.38), indicating that for every additional year supporters have attended the event, they were 1.38 times more likely to support again. The results thus indicate that spectators who are motivated more by Event attractiveness and who have supported the event more times are inclined to attend the race again.

With regard to the other socio-demographic variables, no significant influences on intention to re-visit were found. Based on the signs of the coefficients, the results do however indicate that female, Afrikaans-speaking supporters who stay fewer nights in Cape Town, travel with more people, who have supported the race more times and who are motivated more by Escape and relaxation have a higher intention to support future races. Spectators who are motivated more by Support and socialisation on the other hand, are not inclined to attend the race again.

\section{FINDINGS AND IMPLICATIONS}

Based on the results of the regression analysis, the following findings were revealed: The results first of all contradict the notion by Craggs and Schofield (2009), Kastenholz (2005) and Stewart et al. (2003) that a variety of socio-demographic, behavioural and motivational variables influence travel behaviour, and it this case to support a sporting event. Results from this study shows that it is predominantly socio-demographic variables that influence travel behaviour. These results therefore support the findings by Brown et al. (2008) that socio-demographic variables contribute to spectators' spending. A possible reason for that could be in the motivation to attend the event if one compares spectators with competitors. The significant socio-demographic determinants that influence spending per person were gender, language and province of origin; while the only behavioural determinant was group size. Cannon and Ford (2002:263), Saayman and Saayman (2008), Saayman, Krugell and Van der Merwe (2007:18), Slabbert, Saayman and Saayman (2008:11) and Kruger (2009:28) also found that province of origin (location) plays an important role in the spending of visitors. The results of these studies also indicated that visitors originating from richer provinces, especially Gauteng and the Western Cape tend to spend more. Pertaining to gender, Thrane (2002:284) also found that male visitors spent more than females. However, while the influence of language is evident in this study, a positive correlation with visitor spending is not clear in the tourism literature (Cannon \& Ford, 2002:263; Crouch, 1994:12; Dimara \& Skuras, 2001:690; Lee, 2001:659; Letho et al., 2004:320; Perez \& Sampol, 2000:625). Corresponding with the results, Kruger, Saayman and Ellis (2010), Saayman and Saayman (2008) and Saayman et al. (2009) also found that the increase in the number of people in the travel party leads to a decrease in spending per person. With regard to the significant variables 
influencing repeat attendance and supporters' intention to re-visit, the travel motives Event attractiveness and Support and socialisation significantly influenced repeat attendance while Event attractiveness and the number of times the event has been supported significantly influenced spectators' intention to re-visit. These travel motives are also supported by Wann (1995), Trail and James (2001), Milne and McDonald (1999), Weed and Bull (2004) and Guilianotti (2002).

Secondly, the results also revealed that there was no significant relationship between spectator spending, repeat attendance and intention to re-visit. However, repeat attendance does have a significant influence on spectators' intention to re-visit and spectators who have attended the race more times have a higher intention to re-visit in the future. However, since the influence of the aforementioned motivational and behavioural characteristics has to date received little attention in sport event literature (Cannon \& Ford, 2002; Stewart et al., 2003); these results are therefore neither supported nor contradicted by previous research.

This study has the following implications:

- $\quad$ Spectators are just as important to a sporting event as participants. Therefore event organisers need to cater for their needs as well.

- $\quad$ Since an increase in the number of times spectators attend the race also increases the intention to re-visit in the future, marketers of the Two Oceans event should undoubtedly focus on spectators too, as this will positively contribute to visitor numbers and increased spending at the event. Separate marketing strategies could therefore be implemented for participants and spectators. Hence this event should form part of the attractions portfolio of the city of Cape Town. Marketing campaigns should also include tourism attractions in Cape Town as this will also encourage spectators to stay longer and spend more money in the region.

- $\quad$ For purposes of event sustainability, the positive affiliation between repeat visits and intention to re-visit must be maintained. Management must therefore channel their efforts towards the preservation of- and contribution to Event attractiveness, since both repeat visits and intention to re-visit is strongly dependent on this motivation. Management must therefore generally consider aspects concerning Event attractiveness as a key success factor of the Two Oceans event given its prominence in the results. This will entail continued management efforts that ensure a well-organised event of international calibre that continues to attract world-class athletes and loyal spectators, that ultimately contributes to an atmosphere of camaraderie and socialisation.

- Management should generally increase their focus on spectators. Examples of the latter include spectator competitions; prior, during and after the event and more prominent fan club initiatives can be considered. Considering improving spectators' interaction with the event can only lead to further satisfaction and repeat visitation.

- $\quad$ From a methodological point of view, a comparison between participants of - and spectators to the Two Oceans Marathon should be done in order for more strategic management decisions to be made regarding the future of the event.

\section{CONCLUSION}

The aim of the study was to determine the relationship between spectator spending and repeat visitation. Results from his innovative study showed that although no statistically significant relationship was established, a strong relationship between repeat visits and intention to revisit was found. A significant contribution to the literature is evident since the focus is on spectators at a sports event as opposed to participants. It was the first study of its kind in South Africa and the importance of the role and function of spectators at an event is highlighted. These findings will prompt event organisers to see the role and function of spectators in a more serious light. As a further contribution, prominent differences regarding the participants were evident when compared to previous studies on participants at other South African sports events. Future research endeavours should entail a comparison between participants and spectators of sports events. Event attractiveness must also be analysed in more detail in order to determine the extent to which the event can be used to attract future supporters and not just participants. The study has emphasised a major research shortcoming regarding an invaluable aspect of sports event research, namely spectators; and should be conducted at more sporting events. 


\section{ACKNOWLEDGEMENTS}

The authors gratefully acknowledge the NRF (National Research Foundation) for their financial support for this project. The authors would also like to thank The Old Mutual Two Oceans Marathon for allowing this research to be conducted at the race as well as all the fieldworkers and respondents who participated in the survey.

\section{LIST OF REFERENCES}

ALEGRE, J. \& JUANEDA, C. 2006. Destination loyalty: consumer's economic behaviour. Annals of tourism research, 33(3):684-706.

BAKER, D. \& CROMPTON, J. 2000. Quality, satisfaction and behavioural intentions. Annals of tourism research, 27(3):425-439.

BOUCHET, P., BODET, G., BERNACHE-ASSOLLANT, I. \& KADA, F. 2010. Segmenting sport spectators: construction and preliminary validation of the sporting event experience search (SEES) scale. Sport management review, 1(1):1-12.

BROWN, C., BUSSER, J.A. \& BALOGLU, S. 2008. Sport tourists in a gaming destination: predicting gaming and nongaming

BULL, C. \& WEED, M. 1999. Niche markets and small island tourism: the development of sports tourism in Malta. Managing leisure, 4(1);142-155.

CANNON, T.F. \& FORD, J. 2002. Relationship of demographic and trip characteristics to visitor spending: an analysis of sports travel across time. Tourism economics, 8(3):263-271.

CASSIDY, F. 2005. What motivates sports event tourists? A synthesis of three disciplines.

http://eprints.usq.edu.au/845/1/Cassidy Sept 52005 version.pdf Date of access: 24 May 2010.

DANIELS, M.J. \& NORMAN, W.C. 2003. Estimating the economic impacts of seven regular sport tourism events. Journal of sport tourism, 8(4):214-222.

DE KNOP P. 1999. Sport for all and active tourism. World Leisure and Recreation, 32(3): 30-36.

expenditureshttp://pc.parnu.ee/ htooman/EuroChrie/Welcome\%20to\%20EuroCHRIE\%20Dubai\%2020 08/papers/SPORT\%20TOURISTS\%20IN\%20A\%20GAMING\%20DESTINATION\%20PREDICTING\%2 0GAMING\%20AND\%20NONGAMING.pdf

GETZ, D. 1998. Trends, strategies, and issues in sport-event tourism. Sport marketing quarterly, 7(2):8-13.

GIBSON, H.J. 1998. Sport tourism: a critical analysis of research. Sport management review, 1(1):45-76.

GRATTON, C., DOBSON, N. \& SHIBLI, S. 2000. The economic importance of major sports events: a case-study of six events. Managing leisure, 5(1):17-28.

GRATTON, C., SIMON, S. \& COLEMAN, R. 2005. Sport and economic regeneration in cities. Urban studies, 42(5/6):985-999.

GREIG, M.S. \& McQUAID, R.W. 2003. The economic impact of a sporting event: a regional approach. http://researchrepository.napier.ac.uk/2414/1/econimpGREIG.pdf

HINCH, T. \& HIGHAM, J. 2004. Sport Tourism Development. Clevedon: Channel View Publications. $254 \mathrm{p}$.

http://www.duplication.net.au/ANZMAC09/papers/ANZMAC2009-370.pdf Date of access: 27 May 2010.

KOTZE, N. 2006. Cape Town and the Two Oceans Marathon: the impact of sport tourism Urban forum, 17(3):282-293.

KOZAK, M. \& RIMMINGTON, M. 2000. Tourist satisfaction with Mallorca, Spain, as an off-season holiday destination. Journal of travel research, 38(3):260-269. 
KOZAK, M. 2001. Repeaters' behaviour at two distinct destinations. Annals of tourism research, 28(3):785-808.

KUENZEL, S. \& YASSIM, M. 2007. The effect of joy on the behavior of cricket spectators: the mediating role of satisfaction. Managing leisure, 12(1):43-57.

LACHOWETZ, T. 2001. Regional sports alliance: a conceptual approach. Sport marketing quarterly, 10(1):25-34.

MATHESON, V.A. 2006. Mega-events: the effect of the world's biggest sporting events on local, regional, and national economies. http://www.holycross.edu/departments/economics/website Date of access: 25 May 2010.

MCDONALD, M.A., MILNE, R.G. \& HONG, J. 2002. Motivational factors for evaluating sport spectator and participant markets. Sport marketing quarterly, 11(2):100-113.

OPPERMANN, M. 1998. Destination threshold potential and the law of repeat visitation. Journal of travel research, 37(2):131-137.

OPPERMANN, M. 2000. Tourism destination loyalty. Journal of travel research, 39(1):78-84.

PREUSS, H. 2005. The economic impact of visitors at major multi-sport events. European sport management quarterly, 5(3):281-301.

PREUSS, H., SEGUIN, B. \& O'REILLY, N. 2007. Profiling major sport event visitors: the 2002 Commonwealth Games. Journal of sport and tourism, 12(1):5-23.

REGAN, N., CARLSON, J. \& ROSENBERGER, P.J. 2009. Examining the antecedents of grouporiented travel behavior to large-scale events: a conceptual model and predispositions.

REID, L.J. \& REID, S.D. 1993. Communicating tourism suppliers services: building repeat visitor relationships. Journal of travel and tourism marketing, 2(2/3):3-20.

RITCHIE, B. 2005. Sport tourism. Small-scale sport event tourism: the changing dynamics of the New Zealand Masters Games. (In Novelli, M. Ed. Niche tourism contemporary issues, trends and cases. Oxford: Elsevier. 157-170p.)

ROBINSON, M.J. \& TRAIL, G.T. 2005. Relationship among spectator gender, motives, points of attachment, and sport preference. Journal of sport management, 19(1):58-80.

SAAYMAN, M. \& UYS, C. 2003. Profiling spectators at a one-day international cricket match. Journal of sport tourism, 8(4):293-301.

SAAYMAN, M., SAAYMAN, A. \& DU PLESSIS, C. 2005. Analysis of spending patterns of visitors of three World Cup Cricket matches in Potchefstroom, South Africa. Journal of sport tourism, 10(3):211221.

SCOTT, A.K.S. \& TURCO, D.M. 2007. VFR's as a segment of the sport event tourist market. Journal of sport and tourism, 12(1):41-52.

SCOTT, A.K.S. \& TURCO, D.M. 2009. Distinguishing event spectator spending profiles: projected impacts of the 2009 U.S. Open Golf Championship. Sport management international journal, 5(1):3954.

SMITH, A. 2005. Reimaging the city: the value of sport initiatives. Annals of tourism research, 32(1):217-236.

STANDEVEN, J. \& DE KNOPP, P. 1999. Sport Tourism. Champaign, IL: Human Kinetics.

STEWART, B., SMITH, C.T. \& NICHOLSON, M. 2003. Sport consumer typologies: a critical review. Sport marketing quarterly, 12(2):206-216.

TOOHEY, K., TAYLOR, T. \& LEE, C. 2003. The FIFA World Cup 2002: the effects of terrorism on sport tourists. Journal of sport tourism, 8(3):167-185.

TURCO, D.M. 1998. Residents' perceived social costs and benefits attributed to an international staged attraction. Journal of travel and tourism marketing, 7(1):21-28. 

M. Kruger
K. Botha
M. Saayman

The relationship between visitor spending and repeat visits:

An analysis of spectators at the Old Mutual two oceans marathon

VAN LEEUWEN, L., QUICK, S. \& DANIEL, K. 2002. The sport spectator satisfaction model: a conceptual framework for understanding the satisfaction of spectators. Sport management review, 5(1):99-128.

YOSHIDA, M. \& JAMES. J.D. 2010. Customer satisfaction with game and service experiences: antecedents and consequences. Journal of sport management, 24(1):338-361. 